\title{
APRENDIZAGEM COOPERATIVA BASEADA EM PROBLEMAS E ORQUESTRAÇÃO INSTRUMENTAL NO ENSINO DE CÁLCULO
}

\author{
PROBLEM-BASED COOPERATIVE LEARNING AND INSTRUMENTAL \\ ORCHESTRATION IN CALCULOS TEACHING
}

\author{
EL APRENDIZAJE COOPERATIVO BASADO EN PROBLEMAS Y LA \\ ORQUESTACIÓN INSTRUMENTAL EN LA ENSEÑANZA DEL CÁLCULO
}

\author{
Francisco Eteval da Silva Feitosa $^{1}$ (iD) \\ Roberta dos Santos Rodrigues ${ }^{2}$ (iD)
}

\begin{abstract}
RESUMO
Este trabalho trata da análise do processo de concepção e aplicação de uma orquestração instrumental, por meio remoto, visando a desenvolver a habilidade de resolver problemas, tais como maximizar áreas, volumes e lucros e minimizar distâncias, tempo e custos, isto é, problemas de otimização. Para isso, realizou-se uma pesquisa qualitativa de caráter descritivo na qual aplicamos o método Aprendizagem Cooperativa Baseada em Problemas com 21 discentes do curso de Licenciatura em Matemática da Universidade Federal do Amazonas. Os pressupostos teóricos estão fundamentados na Teoria da Orquestração Instrumental e nos princípios da aprendizagem cooperativa. Os discentes foram divididos em grupos, e as situações de ensino foram trabalhadas em atividades síncronas e assíncronas de modo que, ao final da orquestração, cada grupo apresentou um relatório escrito e uma apresentação oral. A análise dos dados nos possibilitou perceber que a maioria dos discentes apresentou interesse pelo trabalho em grupo e se mostrou satisfeita com a metodologia empregada, desenvolvendo a habilidade de resolver os problemas propostos neste estudo. Além disso, percebeu-se o aumento da satisfação discente com as atividades de ensino, melhora qualitativa na aprendizagem, seu rendimento e diminuição da evasão/desistência.
\end{abstract}

Palavras-chave: Aprendizagem Baseada em Problemas. Cálculo. Orquestração Instrumental.

\begin{abstract}
This work deals with the analysis of the process of conception and application of an instrumental orchestration, through remote means, aiming to develop the ability to solving problems such as maximizing areas, volumes and profits and minimizing distances, time and expenses, that is, problems involving optimization. Thus, a qualitative research with descriptive disposition was made in which we applied the Problem-Based Cooperative Learning method with 21 undergraduate students in mathematics at the Federal University of Amazonas. The theoretical assumptions are based on the Instrumental Orchestration Theory and the basics of the cooperative learning. Students were divided into groups and the situations of teaching were worked out in synchronous and asynchronous activities so that, in the end of the orchestration, each group presented a written report and an oral presentation. The data analysis enabled us to realize that most students showed interest in group work and were satisfied with the methodology employed, developing the ability to solving problems proposed in this

\footnotetext{
${ }^{1}$ Doutorado em Matemática pela Universidade Federal do Amazonas e Pós-Doutorado em Educação Matemática (PUC-SP). Endereço para correspondência: Av. das Oliveiras, n.9, Novo Israel, Manaus, Amazonas, Brasil. CEP: 69039-205. E-mail: sfeitosa@ufam.edu.br.

${ }^{2}$ Graduanda em Licenciatura em Matemática e Bolsista de Iniciação Científica pela Universidade Federal do Amazonas (UFAM), Manaus, Amazonas, Brasil. Endereço para correspondência: Av. Genebra, 4, Conj. Campos Eliseos, Planalto, Manaus, Amazonas, Brasil. CEP: 69045-380. E-mail: roberta10rodrigues@gmail.com.
} 
study. In addition, it was noticed the increasing in student satisfaction with the activities of teaching, an qualitative improvement in their learning and academic achievement and a decrease in evasion/forfeit.

Keywords/Palabras clave: Problem Based Learning. Calculus. Instrumental Orchestration.

\section{RESUMEN}

Este trabajo trata del análisis de la implementación y conducción de una orquestación instrumental, por medios remotos, con el fin de desarrollar la capacidad de resolver problemas como la maximización de áreas, volúmenes y beneficios y la minimización de distancias, tiempos y costos, es decir, problemas de optimización. Para ello, se realizó una investigación cualitativa de carácter descriptivo en la que se aplicó el método de Aprendizaje Cooperativo Basado en Problemas con 21 alumnos del curso de Licenciatura en Matemáticas de la Universidad Federal de Amazonas. Los supuestos teóricos se basan en la teoría de la orquestación instrumental y en los principios del aprendizaje cooperativo. Los alumnos se dividieron en grupos y las situaciones didácticas se trabajaron en actividades sincrónicas y asincrónicas para que, al final de la orquestación, cada grupo presentara un informe escrito y una presentación oral. El análisis de los datos permitió constatar que la mayoría de los alumnos mostraron interés por el trabajo en grupo y se mostraron satisfechos con la metodología empleada, desarrollando la capacidad de resolver los problemas propuestos en este estudio. Además, observamos un aumento de la satisfacción de los estudiantes con las actividades docentes, una mejora cualitativa del aprendizaje y del rendimiento de las mismas, y una disminución de la evasión/incapacidad.

Palabras clave: Aprendizaje basado en problemas. Cálculo. Orquestación instrumental.

\section{INTRODUÇÃO}

Neste trabalho apresentamos uma experiência, em sala de aula, em que foi realizada uma orquestração instrumental, por meio remoto, com a metodologia denominada Aprendizagem Cooperativa Baseada em Problemas, no âmbito do componente curricular Cálculo I, no curso de Licenciatura em Matemática da Universidade Federal do Amazonas (UFAM).

Tal discussão é relevante neste momento, visto que há muito se discutem os propósitos do ensino da Matemática e o esgotamento do atual modelo que se mostra ineficaz, para garantir ao estudante o desenvolvimento de competências específicas, como, por exemplo, utilizar processos e ferramentas matemáticas, inclusive tecnológicas, para modelar e resolver problemas cotidianos, sociais e de outras áreas de conhecimento.

No tocante à disciplina de Cálculo, a metodologia de ensino, tradicionalmente empregada nas universidades, é fundamentada na transmissão/recepção de conhecimentos fixos e acabados, nos quais os conceitos são introduzidos em aulas expositivas, cujo professor apresenta definições, propriedades, exemplos e os alunos resolvem listas de exercícios (DALL'ANNE; TRENTIN, 2018). Isso faz o componente curricular de Cálculo destacar-se, 
negativamente, pelos elevados índices de evasão e reprovação. Está cada vez mais evidente que essa metodologia não promove uma aprendizagem significativa de conhecimentos conceituais nem tampouco consegue encorajar o desenvolvimento de outros tipos de conhecimento valorizados na vida profissional e social.

Diante do exposto, o presente trabalho vai ao encontro do pensamento de Rasmussen, Marrongelle e Borba (2014), ao afirmarem ser fundamental que as pesquisas em ensino e aprendizagem de Cálculo contribuam, de fato, com a prática do professor e de Robert e Speer (2001), que reforçam a urgência da integração entre teoria e prática, em estudos relacionados ao ensino de Cálculo, com destaque a dois tipos de pesquisas relacionadas ao ensino e aprendizagem de Cálculo, as que priorizam teorias e as que priorizam a prática.

Desse modo, a experiência de ensino relatada buscou responder à seguinte questão: o método da Aprendizagem Cooperativa Baseada em Problemas, tendo como suporte a teoria da Orquestração Instrumental, por meio remoto, pode apoiar o ensino e a aprendizagem de Cálculo, mais especificamente, o de resolução de problemas de otimização?

O objetivo do estudo foi conceber e aplicar uma orquestração instrumental, realizada por meio remoto, com a metodologia Aprendizagem Cooperativa Baseada em Problemas, que favoreça a construção do conhecimento do estudante sobre a aplicação das derivadas na resolução de problemas de otimização, tais como maximizar áreas, volumes e lucros e minimizar distâncias, tempo e custos.

Este trabalho está estruturado da seguinte forma: inicialmente, apresentamos os pressupostos básicos das teorias da Orquestração Instrumental e da Aprendizagem Cooperativa. Em seguida, fazemos uma breve apresentação sobre o ABP, seus fundamentos, princípios e elementos constitutivos. Então, apresentamos uma descrição dos estudantes envolvidos no Curso de Licenciatura, com os quais o trabalho foi desenvolvido, o relato da experiência e os resultados obtidos, tanto em relação às avaliações teóricas, quanto às expectativas dos alunos da turma diante dessa nova postura do professor em sala de aula virtual.

\section{FUNDAMENTAÇÃO TEÓRICA}

Nesta seção, serão apresentadas as teorias que fundamentaram este trabalho, a saber, a Teoria da Orquestração Instrumental e a Aprendizagem Cooperativa. 
A Orquestração Instrumental é um modelo teórico que muito tem contribuído com pesquisas que buscam investigar a prática docente, em sala de aula rica em tecnologias, na assistência dada aos estudantes no uso de artefatos para a resolução de situações propostas. Segundo Trouche (2005):

\begin{abstract}
Uma orquestração instrumental é o arranjo sistemático e intencional dos elementos (artefatos e seres humanos) de um ambiente, realizado por um agente (professor) no intuito de efetivar uma situação dada e, em geral, guiar os aprendizes nas gêneses instrumentais e na evolução e equilíbrio dos seus sistemas de instrumentos. É sistemático, porque, como método, desenvolve-se numa ordem definida e com um foco determinado, podendo ser entendido como um arranjo integrado a um sistema; é intencional, porque uma orquestração não descreve um arranjo existente (sempre existe um), mas aponta para a necessidade de um pensamento a priori desse arranjo (TROUCHE, 2005, p. 126, tradução nossa).
\end{abstract}

Os elementos básicos de uma orquestração instrumental são a configuração didática, o modo de execução, ambos caracterizados por Trouche (2004) e a performance didática, caracterizada por Drijvers et al. (2010), ao evidenciar que toda orquestração evolui necessariamente durante a sua execução.

Uma configuração didática é um arranjo particular dos estudantes e dos artefatos (BELLEMAIN, TROUCHE, 2016), isto é, diz respeito à organização dos recursos na aula e pode ser descrita por um conjunto de cenários de exploração didática, para um dado ambiente e para cada situação matemática (TEIXEIRA, MATOS, DOMINGOS, 2016).

Um modo de execução é uma forma de utilização dos artefatos, em uma dada configuração e inclui "as decisões sobre a forma como uma tarefa é introduzida e as formas como o recurso pode ser utilizado e sobre os esquemas e técnicas a serem elaborados e estabelecidos pelos alunos" (DRIJVERS, et al., 2010, p. 215). Para uma configuração proposta, existem vários modos possíveis de sua execução.

Uma performance didática envolve as decisões ad hoc tomadas, durante o ensino, sobre como realmente atuar na configuração didática escolhida e modo de exploração, isto é, o desempenho didático descreve os ajustes que o professor realiza, durante a execução da orquestração, nas configurações didáticas e no modo de execução que ele havia planejado a priori. Que pergunta fazer agora, como valorizar ou não qualquer contribuição específica do aluno, como lidar com um aspecto inesperado da tarefa matemática ou da ferramenta tecnológica, ou outros objetivos emergentes, são exemplos de decisões que fazem parte da performance didática (DRIJVERS, P. et al. 2010). 
Uma orquestração instrumental tem também uma dimensão de tempo que está relacionada com o desempenho didático. Pensar a organização do tempo de aula significa pensar na sucessão de configurações didáticas e de seus modos de execução recorrentes das atividades que o professor havia planejado a priori.

Têm-se, assim, as principais etapas de uma orquestração instrumental, que foram consideradas neste estudo, em conjunto com os princípios essenciais da aprendizagem cooperativa, que serão abordados na próxima sessão.

A aprendizagem cooperativa é uma metodologia na qual pequenos grupos de alunos trabalham juntos em uma tarefa comum. As raízes da aprendizagem cooperativa estão profundas, nas teorias de aprendizagem, que fornecem uma estrutura teórica sólida e uma base conceitual para a aprendizagem cooperativa. De acordo com Johnson e Johnson (1999), existem cinco elementos básicos essenciais que precisam ser incluídos para que uma aula seja cooperativa: interdependência positiva, responsabilização individual, interação promotora, habilidades sociais e processamento de grupo.

O professor garante a interdependência positiva quando assegura que cada estudante perceba que está ligado aos outros de tal maneira a sentir que não terá sucesso algum a não ser que os outros também o tenham. O professor deve estruturar cada aula de modo que cada aluno assuma a responsabilidade de aprender o material designado e certificar-se de que todos os membros do grupo o aprendam também.

O segundo elemento básico é a responsabilidade individual, que existe, quando o desempenho de cada aluno é avaliado individualmente e os resultados são devolvidos ao grupo e ao indivíduo (Johnson \& Johnson, 1989). Cada aluno precisa se responsabilizar em executar a parte do trabalho que lhe foi confiada e que não pode esperar que os outros façam o é seu dever. Além disso, todos os membros do grupo devem estar atentos a perceber quem do grupo está precisando de mais assistência e apoio para concluir a tarefa. Johnson, Johnson e Smith (2014, p.6) afirmam que:

O objetivo da aprendizagem cooperativa é tornar cada membro um indivíduo mais forte por seus próprios direitos. Os alunos aprendem juntos para que possam posteriormente ter um desempenho superior como indivíduos. Para garantir que cada membro seja fortalecido, os alunos são considerados individualmente responsáveis por concluir as tarefas, aprender o que está sendo ensinado e ajudar outros membros do grupo a fazer o mesmo.

A interação promotora acontece, quando os alunos promovem o sucesso uns dos outros, auxiliando, encorajando e elogiando os esforços uns dos outros para aprender. Fazer 
isso resulta em processos cognitivos, como explicar oralmente como resolver problemas, discutir a natureza dos conceitos que estão sendo aprendidos, ensinar o conhecimento aprendido para os colegas, desafiar o raciocínio e as conclusões de uns e outros e conectar o conhecimento presente com o aprendizado passado. Para se conseguir uma interação promotora eficiente, o tamanho do grupo precisa ser pequeno, de dois a quatro membros no máximo.

O sucesso de um esforço cooperativo requer o uso apropriado de habilidades sociais. Com o mesmo propósito e precisão que ensinamos habilidades acadêmicas aos alunos, as habilidades interpessoais e de pequenos grupos, como liderança, tomada de decisão, construção de confiança, comunicação e gestão de conflitos, devem ser ensinadas.

O processamento de grupo tem como objetivo simplificar o processo de aprendizagem para torná-lo mais simples, eliminar ações não qualificadas e inadequadas, melhorar continuamente as habilidades dos alunos em trabalhar como parte de uma equipe e celebrar o trabalho árduo e o sucesso. A partir do processamento de grupo, cada membro maximiza a sua própria aprendizagem e a dos outros para que as formas de melhorar o processo possam ser identificadas (Johnson \& Johnson, 1989).

\section{APRENDIZAGEM COOPERATIVA BASEADA EM PROBLEMAS}

A Aprendizagem Baseada em Problemas (ABP), ou Problem Based Learning (PBL), como é conhecida mundialmente, é uma metodologia de ensino-aprendizagem que se caracteriza pelo uso de problemas para estimular o desenvolvimento do pensamento crítico e das habilidades de solução de problemas e a aquisição de conceitos fundamentais de uma área do conhecimento (RIBEIRO, 2010). Para Neves et al. (2018, p. 68),

\footnotetext{
A aprendizagem baseada em problemas ou do inglês, "Problem Based Learning" (PBL) é um mecanismo didático que coloca o aluno direta e ativamente no centro da aquisição do conhecimento, pois concentra a aprendizagem na busca do conhecimento autônomo, estimula a convivência cooperativa entre os membros dos grupos PBL e induz o aluno a adquirir independência na tomada de decisões.
}

Enemark e Kjaersdam (2018) consideram que a expressão "Aprendizagem Baseada em Problemas" engloba diferentes aspectos do ensino e da aprendizagem, podendo se referir a "conceitos didáticos baseados somente na resolução de problemas ou a conceitos que 
combinem os cursos tradicionais com resolução de problemas por meio do trabalho com projeto" (ENEMARK, KJAERSDAM, 2018, p. 17).

$\mathrm{Na} \mathrm{ABP}$ damos aos alunos um problema para compreender e resolver com o objetivo de fazer com que eles aprendam informações e procedimentos relevantes. Para Johnson et al. (1998, p.92), “a aprendizagem cooperativa é o coração do aprendizado baseado em problemas".

A característica fundamental da $\mathrm{ABP}$ é que, nessa metodologia, um problema é usado para iniciar, direcionar, motivar e focar a aprendizagem de um conceito ou conteúdo. Exige-se do aluno a resolução de um problema que ele ainda não conhece e que precisa ser resolvido. "O problema, seja real ou simulado, é o foco do método a partir do qual o aluno inicia o aprendizado dos conteúdos e das habilidades requeridas, de modo que o problema é a mola propulsora da construção do conhecimento que, ao ser adquirido, será aplicado de volta sobre o problema" (NEVES et al.,2018, p. 70).

Algumas características importantes da ABP precisam ser estimadas na aplicação do método:

\begin{abstract}
A ABP é centrada no aluno para motivar a proatividade, de forma que ele se torne agente da aquisição do próprio conhecimento, é autodirigida, de modo que os alunos possam assumir a responsabilidade de gerar problemas e realizar autoavalições ou fazer avaliações de seus pares, promove a autoreflexão, de forma que os alunos se ajustem às suas próprias estratégias de aprendizagem e monitoram a própria compreensão dos assuntos relacionados ao problema, promove o trabalho cooperativo de modo que os alunos se dispõem a participar ativiamente da aquisição mútua do conhecimento e o professor tem o papel de tutor, isto é, é um facilitador do raciocínio individual e coletivo, um facildiator das dinâmicas em grupo e das relações interpessoais (NEVES et al., 2018)
\end{abstract}

Ao longo de toda a história da ABP, grandes quantidades de pesquisas científicas têm sido publicadas, a fim de atestar sua eficácia quanto à aprendizagem dos alunos, como exemplo, podemos citar os trabalhos de Abdullah et al. (2010), Merritt et al. (2017) e Ajai, Imoko (2015).

Enfim, considerando as características da ABP, podemos destacar que o emprego dessa metodologia visa a induzir a autonomia na busca do conhecimento, a estimular o pensamento e raciocínio elevado, a promover a retenção duradoura de conhecimentos, a promover a autopercepção e a autoconfiança, a estimular a convivência profissional e o trabalho cooperativo e a desenvolver habilidades para a resolução de problemas.

Resolver o problema corretamente é menos importante que participar do processo de coleta e aprendizado das informações e procedimentos relevantes para a sua solução. A ABP 
foi desenvolvida, para pequenos grupos de alunos trabalharem juntos e garantir que as informações e procedimentos relevantes sejam descobertos e dominados por todos os membros do grupo.

A ABP tende a ocorrer, em pequenos grupos de alunos, cujo professor é um facilitador e não um palestrante. Obviamente, se os grupos forem estruturados de forma competitiva ou individualista, o aprendizado resultante será significativamente reduzido (JOHNSON, JOHNSON, 1974). Os grupos de aprendizagem baseada em problemas precisam ser estruturados cooperativamente, tornando a aprendizagem cooperativa a base sobre a qual a aprendizagem alicerçada em problemas seja construída.

Quando a conexão entre a aprendizagem cooperativa e a aprendizagem baseada em problemas é explícita, ela é conhecida como Aprendizagem Cooperativa Baseada em Problemas (JOHNSON, JOHNSON, SMITH, 2014, p.14), conceito utilizado neste artigo.

\title{
4 PROCEDIMENTOS METODOLÓGICOS
}

Esta pesquisa tem uma de abordagem qualitativa. Segundo Creswell (2010, p. 26):

\begin{abstract}
A pesquisa qualitativa é um meio para explorar e para entender o significado que os indivíduos ou os grupos atribuem a um problema social ou humano. O processo de pesquisa envolve as questões e os procedimentos que emergem, so dados tipicamente coletados no ambiente do participante, a análise dos dados indutivamente construída a partir das particularidades para os temas gerais e as interpretações feitas pelos pesquisador acerca do significados dos dados.
\end{abstract}

Quanto aos objetivos, trata-se de uma pesquisa descritiva que, segundo Gil (2008, p. 28), "tem como objetivo primordial a descrição das características de determinada população ou fenômeno ou o estabelecimento de relações entre variáveis".

Quanto aos procedimentos, podemos classificar este estudo como uma pesquisa-ação, que, segundo a definição de Thiollent (1985, p. 14):

é um tipo de pesquisa social com base empírica que é concebida e realizada em estreita associação com uma ação ou com a resolução de um problema coletivo e no qual os pesquisadores e os participantes representativos da situação ou do problema estão envolvidos do modo cooperativo ou participativo.

Para os procedimentos metodológicos do estudo, utilizamos a estrutura própria da concepção de uma orquestração instrumental (configuração didática e modo de execução), 
acrescida dos elementos essenciais da aprendizagem cooperativa baseada em problemas, visando responder à questão da pesquisa, isto é, verificar se essa metodologia, com suporte da teoria da Orquestração Instrumental, pode contribuir ao ensino e à aprendizagem de Cálculo Diferencial, mais especificamente para o desenvolvimento da habilidade de resolver problemas de otimização no contexto do Cálculo I.

\subsection{Configuração Didática}

Os sujeitos partícipes da orquestra foram 21 estudantes de graduação de um curso de Licenciatura em Matemática que cursavam, por meio remoto, Cálculo I, no segundo semestre de 2020. Esses estudantes formaram grupos de 4(quatro) a 5(cinco) membros, embora se saiba, como já explicado anteriormente, que os grupos devem ser formados por, no máximo, 4(quatro) membros. Porém, como a turma era composta por 21 estudantes, foi necessário flexibilizar a composição de um dos grupos com 5(cinco) membros. Os estudantes tiveram a liberdade de formar seus grupos. Outros sujeitos da orquestração foram os pesquisadores, sendo que um foi também o professor do componente curricular, uma bolsista de iniciação científica que atuou como tutora e 2 (dois) estudantes que atuaram como monitores.

O professor tinha a função de coordenar os encontros síncronos, de preparar as videoaulas sobre a parte teórica do conteúdo e enviar a tempo para os alunos assistirem a elas, antes de cada encontro. A tutora tinha como objetivos acompanhar a realização e entrega das atividades de cada grupo e atuar como mediadora durante os processamentos de grupo. Os monitores atuavam na orientação dos estudantes quanto à resolução dos problemas.

Nos grupos, havia os papéis de líder e porta-voz que eram indicados pelos membros do próprio grupo. O primeiro tinha a função de, além de executar a parte do trabalho que lhe foi confiada, coordenar os trabalhos, perceber quem do grupo estava precisando de mais assistência e apoio, para concluir a tarefa e pelo envio ao professor das atividades de todos os membros, no prazo estipulado. O segundo tinha a função de, durante as aulas, apresentar a resolução (ou ideias do grupo) de um dos problemas pelos quais o grupo ficou encarregado de resolver. Os estudantes deveriam fazer o revezamento dessas funções no grupo. Objetivamos, assim, garantir a responsabilidade individual e o desenvolvimento de habilidades sociais.

O tempo destinado para a orquestração foi de 2 (duas) semanas. Durante esse período, foram realizados 6(seis) encontros síncronos entre estudantes e pesquisadores, além de 3(três) a 6(seis) encontros síncronos entre monitores e estudantes e mais 2(dois) encontros síncronos 
entre estudantes e tutor. Os grupos podiam fazer encontros assíncronos (sem a presença de professor e tutor) livremente. Essa dinâmica de trabalho foi possível, porque os estudantes estavam cursando somente esse componente curricular nesse período.

Foram 4 (quatro) fichas de trabalho com os problemas a serem resolvidos pelos estudantes, sendo que uma denominamos de principal e as demais de secundárias. As fichas secundárias continham exercícios e problemas que os grupos deveriam resolver de modo a adquirir repertório suficiente para resolver os problemas da ficha principal. No Quadro 1, apresentamos os demais recursos usados por todos os sujeitos da pesquisa.

\begin{tabular}{|c|c|c|}
\hline \multirow{2}{*}{ Recursos } & \multicolumn{2}{|r|}{ Objetivos } \\
\hline & Para os estudantes & Para o professor, tutor e monitores \\
\hline $\begin{array}{c}\text { Geogebra e } \\
\text { calculadora científica }\end{array}$ & Resolver os problemas. & $\begin{array}{l}\text { Usar nos encontros síncronos para auxiliar na } \\
\text { explicação da teoria e de exemplos. }\end{array}$ \\
\hline Google Meet & $\begin{array}{c}\text { Realizar encontros síncronos do } \\
\text { grupo. }\end{array}$ & $\begin{array}{c}\text { Realizar e gravar encontros síncronos com os } \\
\text { estudantes. }\end{array}$ \\
\hline WhatsApp & $\begin{array}{l}\text { Realizar discussões e troca de } \\
\text { informações acerca do trabalho. }\end{array}$ & Enviar orientações aos estudantes. \\
\hline Google Sala de Aula & $\begin{array}{l}\text { Organizar as tarefas, aumentar a } \\
\text { colaboração e melhorar a } \\
\text { comunicação. }\end{array}$ & $\begin{array}{c}\text { Organizar as tarefas, aumentar a colaboração } \\
\text { e melhorar a comunicação. }\end{array}$ \\
\hline Mesa digitalizadora & - & Realizar as aulas. \\
\hline Jamboard & $\begin{array}{l}\text { Resolver os problemas de forma } \\
\text { colaborativa online. }\end{array}$ & $\begin{array}{l}\text { Resolver os problemas de forma colaborativa } \\
\text { online. }\end{array}$ \\
\hline
\end{tabular}

Quadro 1 - Recursos usados por todos os sujeitos da pesquisa Fonte: Elaborado pelos autores.

A interdependência positiva foi estruturada, a partir do sistema de avaliação, que foi implementado. A nota de estudante foi atribuída, segundo os seguintes critérios: frequência às aulas (NFA), frequência na monitoria (NFM), frequência na tutoria (NFT), entrega das atividades pós-aula (NA), nota da entrega da ficha de problemas principal (NFP) e nota da avaliação individual (NAI). Cada nota foi obtida pela média aritmética entre a nota individual obtida pelo estudante e a nota média obtida por sua equipe. Deste modo, quanto maior fosse a nota de cada membro, maior seria a nota do grupo e vice-versa.

\subsection{Modos de Execução}

No primeiro encontro síncrono entre professor/pesquisador e estudantes, foi explicado como a orquestração se desenvolveria. Ao término desse encontro, cada grupo recebeu a ficha de trabalho principal, contendo 6 (seis) problemas do tipo desafios acadêmicos (GORDON, 1998) sendo o $6^{0}$ denominado de problema-desafio por sua maior complexidade em relação 
aos demais. Esse problema-desafio foi o único problema comum a todos os grupos.

Foram estipulados 3 (três) dias, para que os problemas fossem lidos de forma clara e atenta, a princípio, individualmente e, em seguida, por todo o grupo. Os estudantes foram orientados a realizar discussões do tema com base em seus conhecimentos prévios. Um formulário eletrônico foi enviado aos grupos para que, a partir da leitura e discussões, levantassem as palavras-chave, as palavras desconhecidas, as dúvidas pertinentes, formulassem hipóteses para a resolução dos problemas e, então, definissem os objetivos a serem alcançados e todos os assuntos que deveriam ser estudados sobre o tema.

Nos encontros dos estudantes com os monitores, todas as questões levantadas individualmente foram compartilhadas durante as discussões. Foram disponibilizados 6 (seis) encontros de $2 \mathrm{~h}$ cada, para o atendimento da monitoria, sendo que cada estudante deveria participar de pelos menos 3(três) deles por semana. Os discentes reuniram-se com a tutora, em dois encontros síncronos, para que pudessem acompanhar o processamento de grupo.

Os vídeos com a explicação teórica eram disponibilizados antes para que todos pudessem estudar a teoria com antecedência. Esses encontros eram gravados e disponibilizados para os estudantes. Os encontros com o professor se davam por meio do Google Meet e eram divididos em dois momentos e visavam a aprofundar o assunto e complementar tudo o que foi levantado e discutido pelos grupos.

No primeiro momento, um discente de cada grupo apresentava 1(um) problema da ficha de problemas do grupo, tendo sido resolvido ou não. A ideia foi promover um debate amplo entre toda a turma, propiciando uma aprendizagem colaborativa entre os grupos. A escolha desse discente ficava a cargo de cada grupo. A única condição imposta era que deveria ser escolhido 1(um) discente diferente para cada encontro. No segundo momento, 1(um) membro de cada equipe apresentava a resolução de 1(um) problema da lista de exercícios/problemas complementares.

\section{PERFORMANCE DIDÁTICA}

A performance didática foi feita a partir da análise das interações entre os sujeitos do estudo. Durante os encontros síncronos entre professor/pesquisador e discentes, um membro de cada grupo apresentava a solução de um problema de sua ficha de problemas (Figura 1). A primeira decisão ad doc (DRIJVERS et al., 2010), que foi necessário tomar, foi motivada pela dificuldade dos discentes a apresentar a sua resolução do problema. Decidimos, então, que o 
líder enviasse para o WhatsApp da turma um print de sua resolução (Figura 2), para que pudéssemos baixar no computador e projetar na tela de apresentação do Google Meet. O resultado foi muito positivo, e essa estratégia foi adotada no decorrer da orquestração.

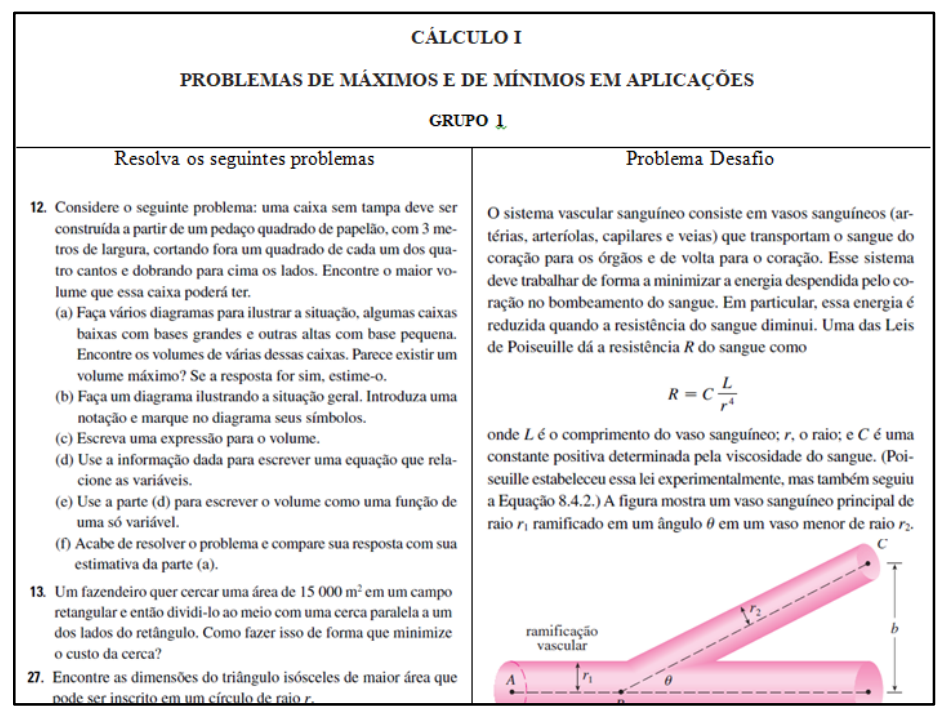

Figura 1 - Print de parte de uma ficha de problemas. Fonte: Próprios autores.

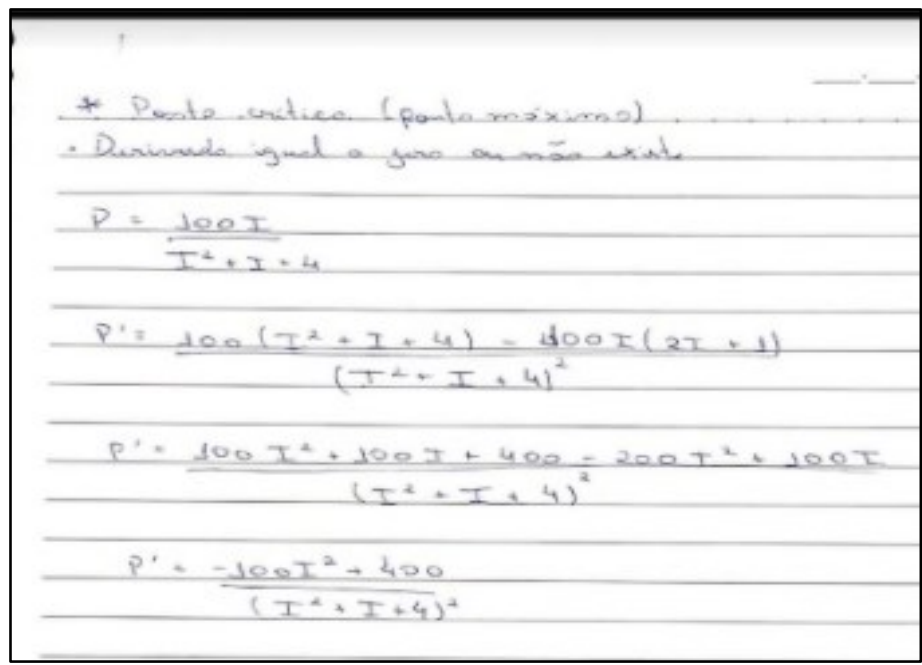

Figura 2 - Print do caderno de um dos discentes enviado pelo WhatsApp. Fonte: Próprios autores.

Outra situação que nos levou a integrar um recurso que não havíamos previsto surgiu quando os discentes precisaram mostrar como se resolvia o seguinte problema: 
Em cada parte, esboce o gráfico de uma função $f$ com as propriedades indicadas e discuta os sinais de $f^{\prime}$ e de $f^{\prime \prime}$.

(a) A função fé côncava para cima e crescente no intervalo $(-\infty,+\infty)$.

(b) A função fé côncava para baixo e crescente no intervalo $(-\infty,+\infty)$.

Quadro 2 - Questão proposta.

Fonte: Próprios autores.

Nesse momento, decidimos usar o Jamboard (Figura 3), que é um quadro interativo desenvolvido pelo Google, que permite que vários usuários possam trabalhar e compartilhar projetos dentro da sua tela, podendo adicionar desde notas adesivas até vídeos.

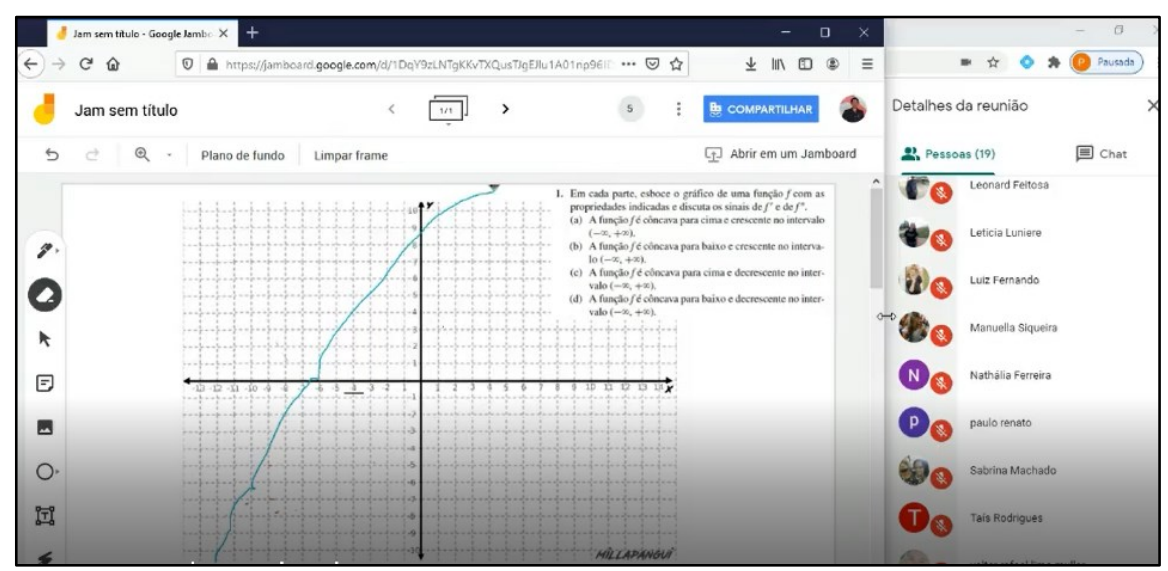

Figura 3 - Print de tela de um discente utilizando o Jamboard durante um dos encontros. Fonte: Próprios autores.

Os encontros tiveram foco em questões conceituais (Figura 4), deixando questões procedimentais para serem realizadas em atividades assíncronas. Nossa experiência mostra que, quando os alunos encontram dificuldades, uma estratégia dominante de enfrentamento é se concentrar nos aspectos processuais que geralmente exigem menos deles, o que pode ter um efeito limitador em suas atitudes, quando eles fazem um curso mais rigoroso em um estágio posterior (TALL, 1993). 


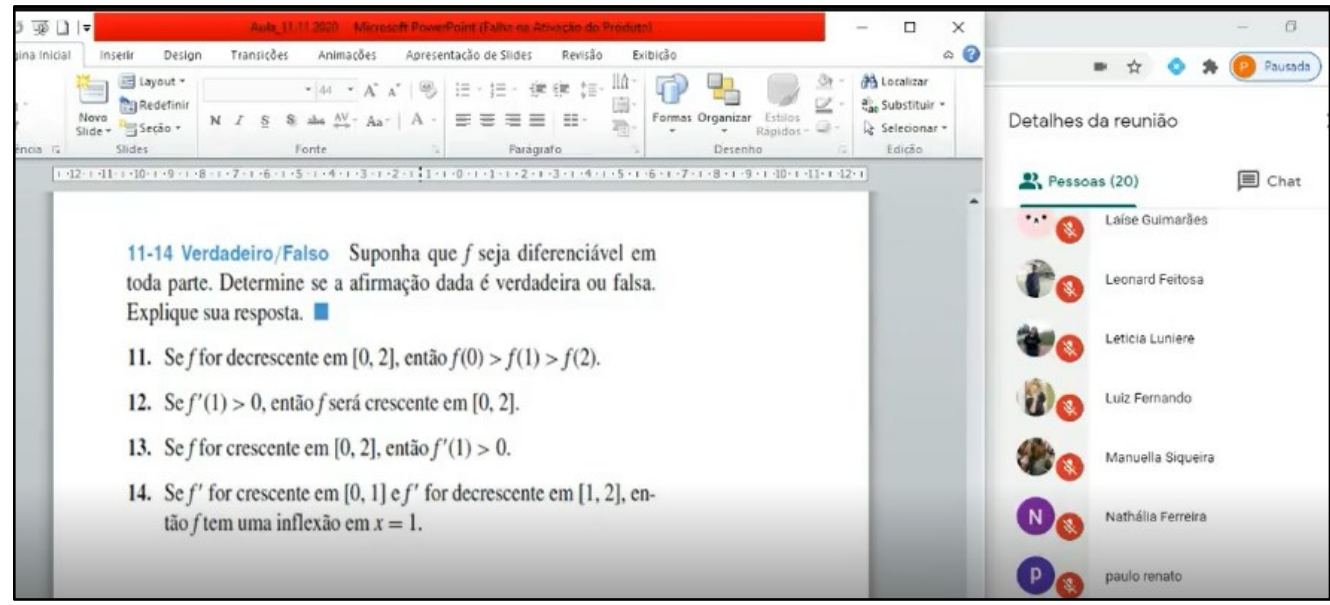

Figura 4 - Print de tela de um dos encontros professor-discentes, abordando questões conceituais. Fonte: Próprios autores.

Segundo Glasser (2017), o aluno constrói seus conhecimentos de forma mais concreta e eficaz, quando discute com outras pessoas, quando faz e quando ensina aos outros. Por isso, durante os encontros, pedíamos que eles pensassem e se dedicassem a promover um diálogo visando a promover a compreensão e o seu crescimento. Com o intuito de tornar as aulas interativas com os alunos, desenvolvendo raciocínios e se comunicando, em cada encontro, pelo menos 2(dois) discentes de cada grupo explicavam à turma um problema da sua ficha de problemas e 1(um) exercício/problema da lista complementar (Figura 5).

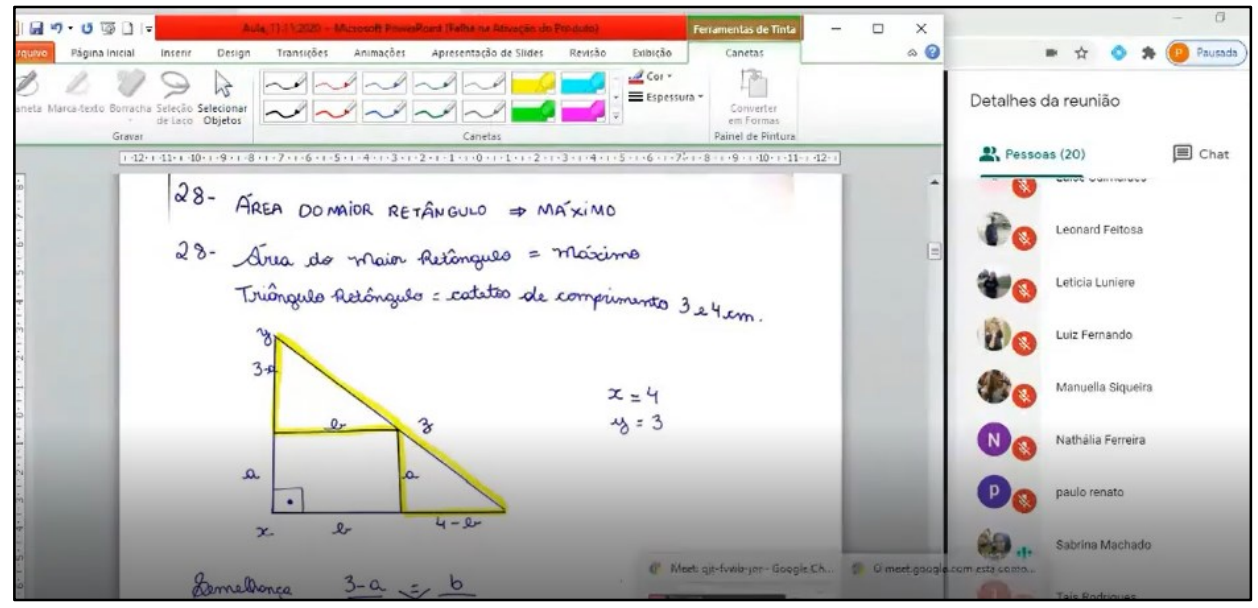

Figura 5 - Print de tela de um dos discentes, explicando a resolução de uma questão. Fonte: Próprios autores.

Alguns alunos precisam de um tratamento especial, como uma sessão de tutorial adicional para corrigir seus equívocos (TARMIZI, 2010), como, por exemplo, mudar seus hábitos de estudo trazidos do ensino médio para o ensino superior que, comprovadamente, 
não funcionam (DE JESUS, 2019).

Diante do exposto, no início dos trabalhos, os discentes foram informados de que a presença na monitoria e na tutoria seria obrigatória e geraria uma nota que comporia sua nota final. Ademais, o grupo recebia uma nota pela média das notas obtidas por cada membro, criando assim uma interdependência positiva e a responsabilidade individual. Ressaltamos que, constantemente, incentivávamos os discentes a participar desses encontros, mostrandolhes os benefícios que eles teriam.

Em relação à monitoria, tivemos que tomar algumas decisões ad doc para contornar alguns imprevistos. Primeiro foi a resistência de alguns membros em participar das sessões de monitoria, o que iria prejudicar bastante o desempenho do grupo. Para resolver essa situação, os pesquisadores conversaram em particular com esses discentes para saber o que estava havendo e por que de eles não participarem desses encontros. Mesmo assim, alguns continuaram não participando e, para não prejudicar o grupo, a nota desses discentes foi calculada à parte.

Outra situação foi o fato de alguns alunos não terem dúvidas sobre as atividades propostas, por isso, não quererem ficar na monitoria. Resolvemos, então, que, para que não ficassem durante todo o encontro, poderiam pedir ao monitor duas ou três questões da lista de exercícios para que pudessem resolver e mostrar que não tinham dúvidas. Após responder a essas questões, o discente poderia sair da sessão da monitoria sem prejuízo.

A interação entre sujeitos que buscam aprender algo junto, nesse caso, por meio da aprendizagem cooperativa, é um ponto crucial, para que haja a efetiva construção do conhecimento, pois possibilitará a troca de ideias e discussões a respeito do assunto em questão (DA SILVA, 2018).

Por esse e outros tantos motivos que os discentes foram incentivados a interagirem, ao máximo, para resolverem as atividades propostas, fosse pelos grupos de WhatsApp, ou até por encontros no Google Meet, os quais foram organizados pelos próprios alunos. Além disso, cada grupo dispôs de dois encontros síncronos com a tutora, a qual thes explicou como funcionariam as atividades, durante o período do projeto, além das metodologias de ensino/aprendizagem que seriam colocadas em prática, mostrando-lhes a finalidade de cada uma delas e formas para que eles pudessem se adaptar mais facilmente a esse modelo de aula.

O primeiro encontro síncrono, realizado entre a tutora e um dos grupos de alunos, que se caracterizou como um encontro adicional, foi para preencher o formulário "Leitura e identificação do(s) problema(s)", para o qual os discentes tinham que fazer uma análise, em 
grupo, das questões da lista de exercícios sobre otimização e identificar aspectos, como palavras-chave de cada problema, dúvidas que surgiram após a leitura dos enunciados, entre outros fatores, e a função da tutora foi a de orientar os alunos, durante essa discussão, além de coletar dados relevantes para a pesquisa.

Os estudantes participantes do encontro estavam bem empenhados, procurando as respostas às perguntas do formulário e, à medida que iam se aprofundando na análise das questões, passaram a notar pontos, em suas respostas, que poderiam ser melhorados ou corrigidos, como termos que eles inicialmente julgaram como palavras-chave, na verdade, eram irrelevantes para a resolução da questão.

Os discentes tinham o costume de marcar encontros pelo Google Meet, para resolverem as listas de exercícios juntos e discutirem as questões de forma síncrona. Durante esses encontros, um dos alunos apresentava a sua tela com a lista de questões, para que os colegas também pudessem ver e, assim, iam resolvendo as atividades, questão por questão, tirando as dúvidas uns dos outros e, ao final de cada problema, discutiam as respostas e as formas de resolução.

Outra maneira como os alunos interagiam era pelos grupos de WhatsApp, por meio dos quais eles enviavam prints de suas resoluções para os colegas analisarem, além de compartilhar suas dúvidas, incentivar os outros membros do grupo a concluírem as listas de exercícios, discutirem quem seria o líder de tal dia, qual deles iria apresentar a questão, durante o horário de aula e enviar as listas, para o líder do dia anexar ao formulário de entrega.

Com o passar dos dias, foi-se percebendo maior complexidade nas discussões dos alunos, nas ferramentas utilizadas para resolverem as questões, como o software GeoGebra. No entanto muitos expressaram dificuldade em saber o que o problema exigia, já que os enunciados da lista de otimização determinavam que interpretassem o contexto colocado e analisassem os dados para, assim, resolverem a questão.

Os discentes que apresentaram tal dificuldade alegaram que sabiam como fazer os cálculos necessários para a resolução, mas não sabiam como aplicá-los no problema. Entretanto, depois de algumas orientações, passaram a procurar as palavras-chave de cada questão, anotar os dados importantes, antes de resolvê-la, superando assim o obstáculo apresentado inicialmente. 


\section{ANÁLISES E RESULTADOS}

Diante da análise das soluções apresentadas pelos discentes, ao longo do estudo, percebemos indícios de aprendizagem, em relação aos conceitos e propriedades abordados nas atividades e uma evolução na qualidade das resoluções apresentadas pelas equipes dos problemas propostos, estimando as quatro etapas da resolução de um problema descrito por Pólya, isto é, a compreensão do problema, elaboração de um plano, execução do plano e verificação dos resultados. Nas Figuras 6 e 7, apresentamos as resoluções de um problema apresentado pelo grupo 4 no $3^{\circ}$ encontro e a resolução de um problema apresentado pelo mesmo grupo no $6^{\circ}$ e último encontro.

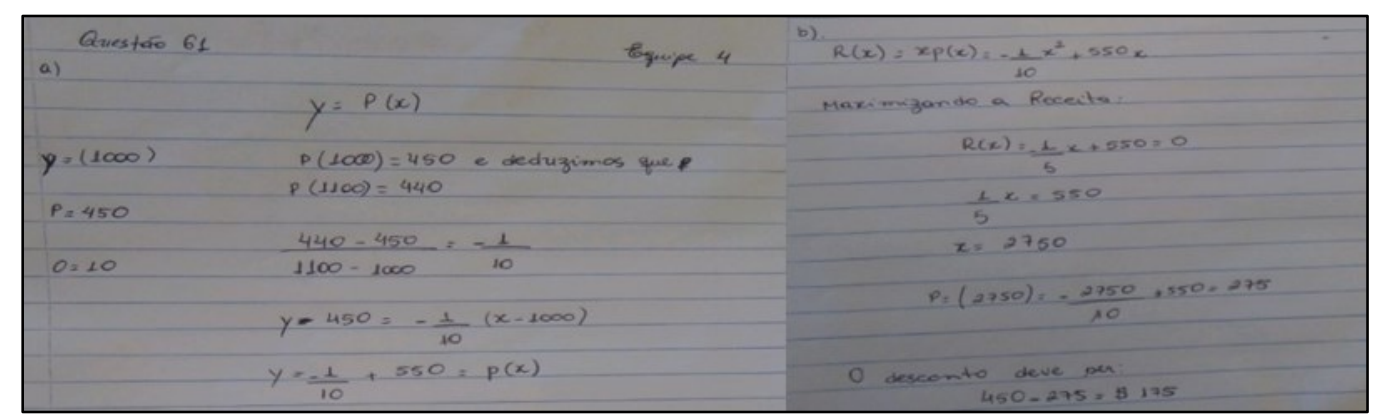

Figura 6 - Resolução de um problema apresentado pelo grupo 4 no $3^{\circ}$ encontro. Fonte: Elaborado pelos pesquisadores.

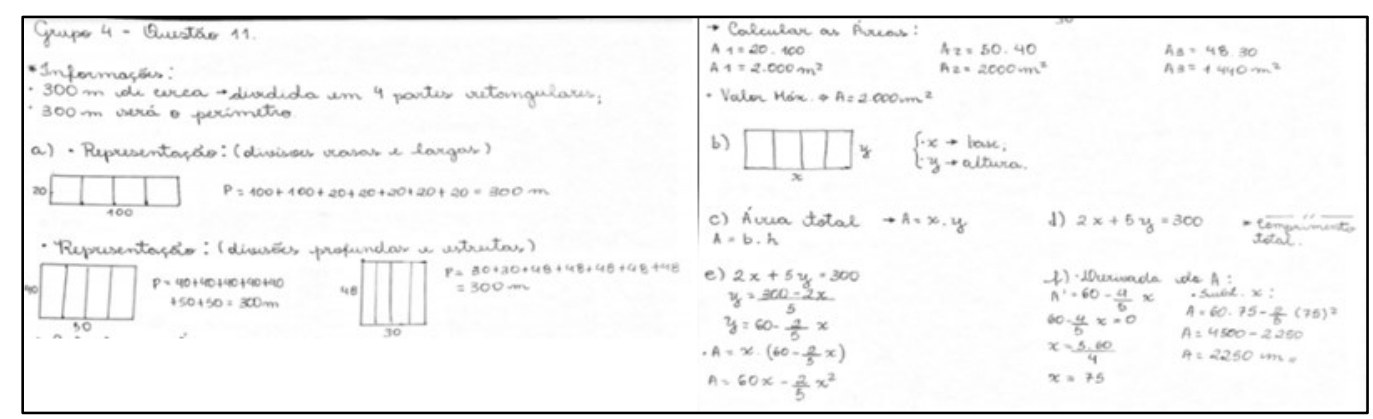

Figura 7 - Resolução de um problema apresentado pelo grupo 4 no $6^{\circ}$ e último encontro. Fonte: Elaborado pelos pesquisadores.

Vejamos, por exemplo, a evolução da qualidade na resolução de problemas apresentado pelo grupo 3 (Imagens 8, 9 e 10). Na resolução de um problema apresentado por esse grupo no $6^{\circ}$ encontro, o grupo identifica os dados, o objetivo e as condições apresentadas e deixa claro quais os cálculos e suas estratégias para resolver o problema. A compreensão do problema pode ainda ser evidenciada na resposta dada, em língua natural, ao final da resolução. 


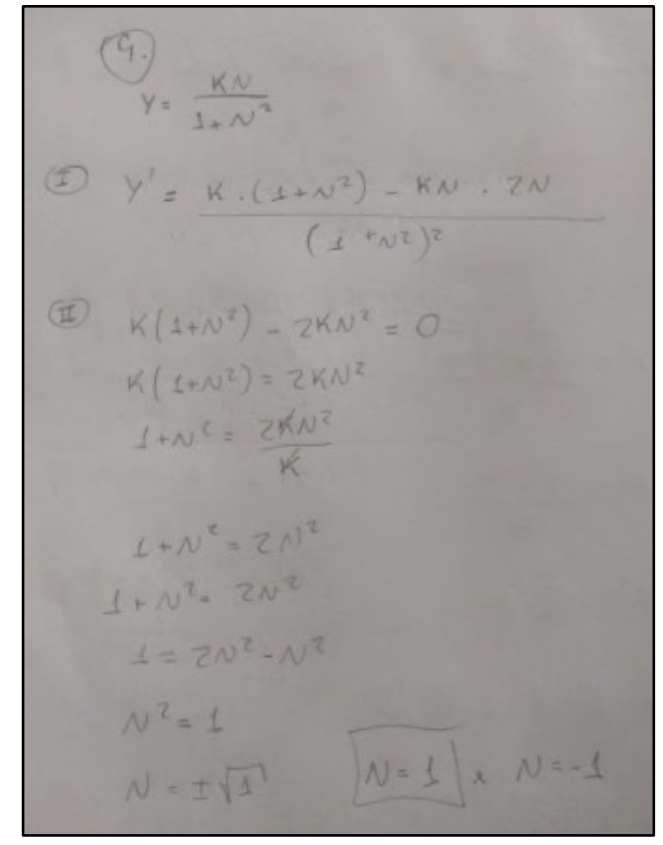

Figura 8 - Resolução de um problema apresentado pelo grupo 3 no $1^{\circ}$ encontro.

Fonte: Elaborado pelos pesquisadores.

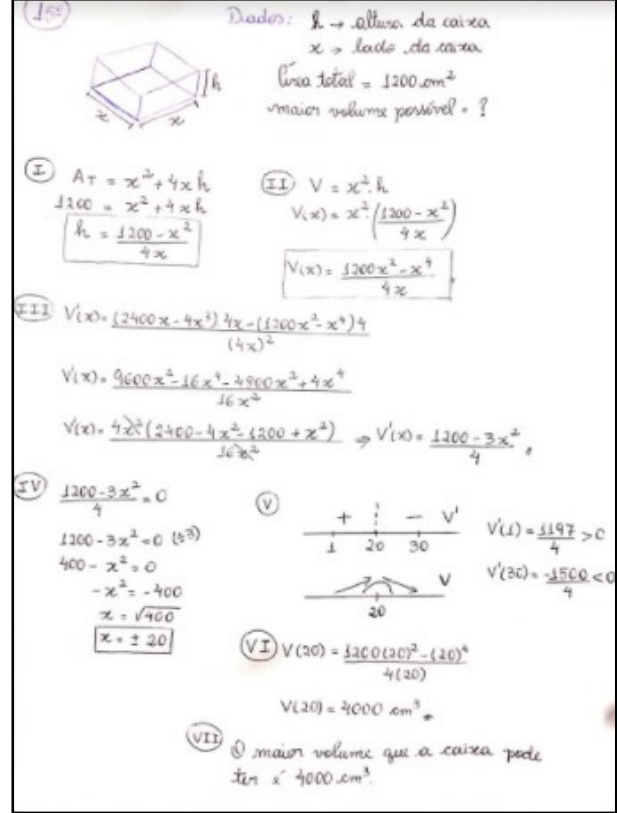

Figura 9 - Resolução de um problema apresentado pelo grupo 3 no $3^{\circ}$ encontro

Fonte: Elaborado pelos pesquisadores.
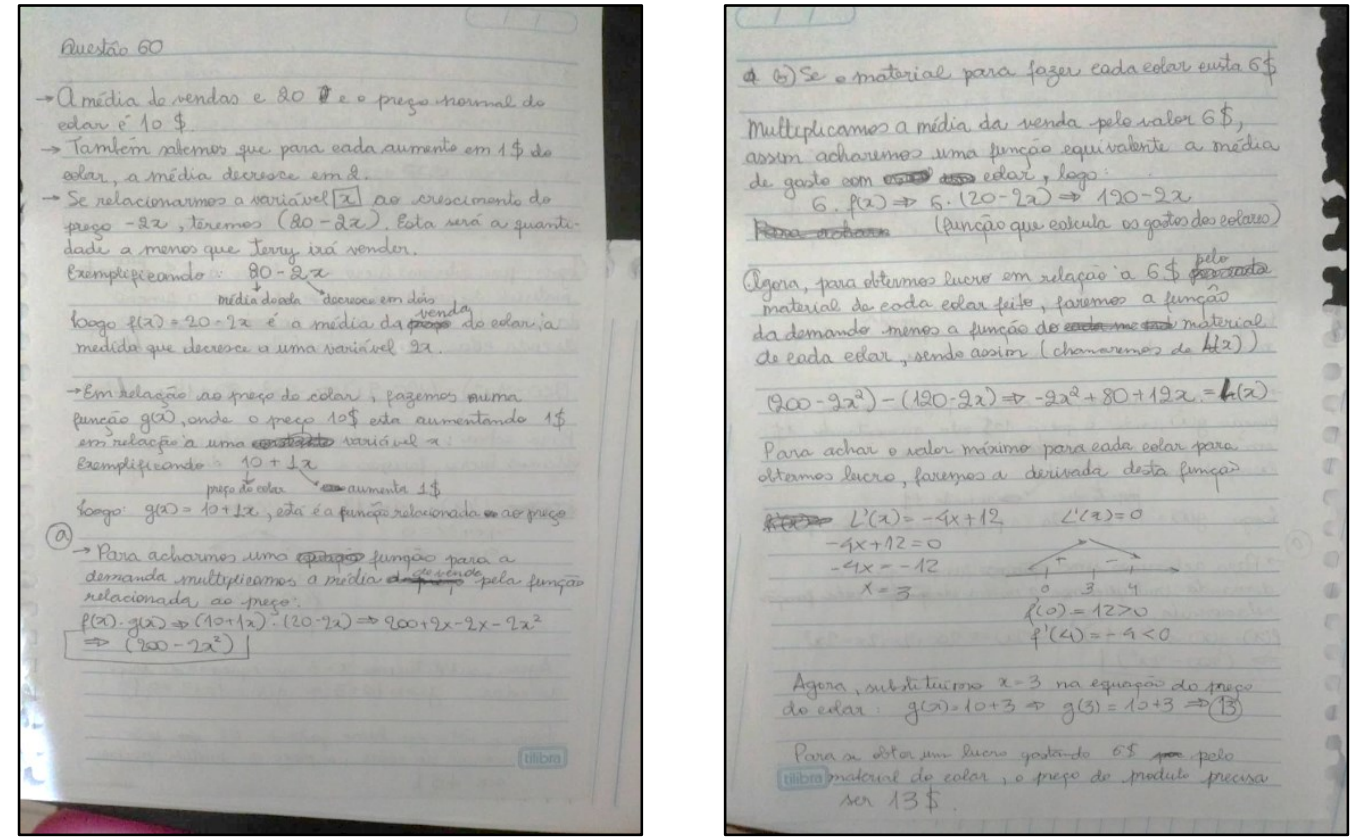

Figura 10 - Resolução de um problema apresentado pelo grupo 3 no $6^{\circ}$ encontro. Fonte: Elaborado pelos pesquisadores.

Avaliar trabalho em grupo não é fácil, porque muitas artimanhas podem desvirtuar o processo, sendo difícil fazer um acompanhamento preciso da aprendizagem somente pelo produto final apresentado. Ao implementar os princípios básicos da aprendizagem cooperativa, garantimos, de certo modo, um controle no sentido de permitir uma avaliação 
contínua dos discentes. Contudo julgamos ser importante uma avaliação por discentes em relação ao trabalho em grupo e à metodologia empregada.

Para tanto, usamos parte do modelo de questionário elaborado por Cohen e Lotan (2017) a fim de que os alunos avaliassem o trabalho em grupo. Usamos o Formulário Google, para que eles respondessem a esse questionário, cuja análise das respostas passaremos a apresentar nos próximos parágrafos.

Em relação ao trabalho em grupo, $76,2 \%$ dos discentes disseram que seu nível de interesse pelo trabalho em grupo foi muito interessado ou razoavelmente interessado. Quando questionados sobre seu nível de dificuldade encontrado no trabalho em grupo, 42,9\% afirmaram não ter sido muito difícil, apenas o suficiente.

Nas atividades propostas pelo professor, somente 1(um) discente respondeu que não entendia exatamente o que o grupo deveria fazer. E, durante os encontros do grupo para resolver os problemas, novamente apenas 1(um) aluno afirmou que nunca falava e, se haviam falado menos que gostariam, a principal razão apontada para isso foi o medo de declarar sua opinião $(19 \%)$.

Quando questionados sobre sua relação com os demais membros do seu grupo, 95,2\% afirmaram haver se entendido bem com todos eles ou com a maioria deles e todos disseram que trabalhariam novamente com o mesmo grupo numa outra oportunidade.

Solicitamos que os discentes falassem como foi sua experiência em relação à atividade desenvolvida pelo líder que ficava encarregado de receber as listas dos membros e responsável por enviar as listas ao professor. De modo geral, os alunos gostaram da experiência. Apenas 1(um) discente relatou que não gostou, mas não explicou o motivo. Destacamos, a seguir, os comentários de 5(cinco) discentes:

Discente 1: Em relação a quando eu fui a líder deu tudo certo, conseguimos nos ajudar e nos organizar certinho quanto ao prazo, não foi preciso pressionar ninguém, exceto a uma integrante do grupo que não participa de nenhuma discussão, mas todos entregaram tudo concluído e dentro do prazo. Acho que essa dinâmica faz com que a gente interaja mais com o grupo, o que é bom.

Discente 2: O principal problema é que nem todos terminavam os exercícios no mesma hora, então o líder tinha que aguardar o último a envia, as vezes até quase meia noite, pra entregar as atividades.

Discente 3: Muito estressante, porém foi um trabalho necessário cobrar as atividades e ter a responsabilidade de enviar as mesmas. O único fator que me incomodou foi em relação ao horário do prazo que ficava para muito tarde e o líder tinha que ficar acordado até tarde esperando que todos enviassem.

Discente 4: Achei um pouco incômoda, pois cada um tem a sua própria rotina e faz no seu tempo, a maioria não pode esperar até o limite da entrega e isso complica para aqueles que não conseguem fazer mais cedo ou aqueles que tiveram dificuldade no processo. 
Discente 5: Um pouco dificil, pois tinha que cobrar para os membros entregarem. Alguns não deram trabalho mas outros sim.

(Respostas dos discente, 2020).

Podemos perceber no relato dos discentes que o maior desafio, ao ser o líder, foi fazer com que seus pares entregassem as atividades dentro de um tempo hábil para que ele, o líder, pudesse enviá-las ao professor.

Quando perguntados acerca das metodologias empregadas, 80,9\% disseram ficar muito satisfeitos ou satisfeitos em relação à metodologia aprendizagem baseada em problemas. Quanto à metodologia aprendizagem cooperativa, 76,2\% afirmaram estar muito satisfeitos ou satisfeitos. Isso se refletiu na frequência dos discentes nos encontros síncronos com o professor que chegaram a $81,17 \%$.

Em relação à metodologia sala de aula invertida, 57,1\% disseram que ficaram muito satisfeitos ou satisfeitos. Segundo os discentes, o fato de os vídeos terem duração relativamente longa, cerca de $1 \mathrm{~h} 30 \mathrm{~min}$, tornava-se cansativo e eles alegaram perder a concentração facilmente. Ressaltamos que os vídeos eram gravados pelo próprio professor e continham a teoria necessária para a resolução dos problemas. O objetivo foi aproveitar todo o tempo nos encontros síncronos para a apresentação e a discussão de problemas. Seguem as respostas de alguns discentes quanto às metodologias.

Discente 1: Já a metodologia cooperativa, principalmente em relação aos membros do grupo, foi bastante eficaz, pois trocamos ideias em relação ao conteúdo e aos problemas, tiramos dúvidas entre si e acabou gerando mais entendimento do assunto.

Discente 2:As metodologias usadas foram bem produtivas, e de uma forma que podíamos interagir mais com os membros do grupo para a aula online. Minha aprendizagem em particular foi muito boa, só não em taxas relacionadas, no entanto o restante foi muito bom.

Discente 3: Bom, é um método bastante prático, logo isso nos conduz a praticar mais a matemática e isso é um ponto positivo, negativos acho que não tenho nenhum! Sobre aperfeiçoamento, o modo que está, é bom, então continuaria nesse método!

Discente 4: Essa metodologia nós levar a pensar nos problemas a resolver, quais ferramenta a usar, em muitas etapas não conseguimos resolver os exercícios pois não tínhamos os conhecimentos necessários pra a questão. Contudo ao decorrer dos conteúdo conseguimos absorver os conhecimentos e resolver as problemáticas.

Discente 5:Muito boa, pois me estimulou a procurar estudar os assuntos mais profundamente, além de poder contar com a colaboração do meu grupo na resolução de determinadas questões. Entretanto me senti um pouco sobrecarregada, por talvez não saber administrar o meu tempo em relação à resolução das listas de exercícios.

Discente 6: A melhor forma de aprender e concretizar esse aprendizado é explicando para alguém e discutindo nossos erros. Repetir várias vezes uma mesma resolução, explicar várias vezes pra um colega de formas diferentes e até a pressão de querer fazer certo nos encontros com a turma, mesmo me sentindo mais a vontade para errar, foi essencial para compreender certas coisas que, por conta 
própria, eu demoraria mais tempo para compreender. Então essa metodologia, tanto a de cooperação com a equipe quanto a sala de aula invertida foram métodos muito benéficos em todos os aspectos. Não tenho nenhum ponto negativo para comentar e acho que está funcionando bem da forma que estamos trabalhando.

Discente 7: as resoluções eram muito rápidas e eu não compreendia as questões como deveria, e sobre as videoaulas gravadas, o tempo ficada corrido para vê-las completamente.

Discente 8: Deixou as aulas mais dinâmicas, apertou mais o horário dos alunos por ter que assistir mais 1 hora de aula e ter que assistir a aula ao vivo. Se o sistema da lista de grupo continuar, talvez limitar as questões das listas individuais.

Discente 9: Os aspectos positivo são, a participação de todos na aula, cada um podendo expor seu aprendizado com as aulas invertidas, interação entre os membros do grupo.

Discente 10: Pontos negativos são mais com relação tempo, para assistir as aulas invertidas e entregar das atividades.

(Respostas do discente quanto as metodologias, 2020).

Acerca da contribuição da monitoria para sua aprendizagem, 57,1\% disseram que muito ajudou ou ajudou e $85,7 \%$ disseram que a tutoria muito ajudou ou ajudou para a sua aprendizagem. Solicitamos que os discentes escrevessem sua visão acerca de como foram realizadas a monitoria e a tutoria, destacando aspectos positivos, negativos e sugestões para o aperfeiçoamento do trabalho.

Discente 1: A monitoria é bem interessante e muito importante, pois nela conseguimos ter uma visão melhor sobre os problemas e assim conseguimos resolver as questões com facilidade. No entanto, nem sempre estamos disponíveis para assistir aulas em determinados horários. E a internet também não colabora.

Discente 2: Paciência pra explicar questões tanto na monitoria como na tutoria. Um ponto negativo foi um dos monitores não colaborou muito.

Discente 3: Nada a acrescentar sobre a monitoria de um dos monitores, mas insatisfeita com a monitoria do outro, que muitas vezes foi grosso e com má vontade.

Discente 4: Na monitoria escolhi apenas um monitor, pois já tinha confiança nele que ele era um bom monitor e influenciador, grato demais pelas ajudas que ajudaram muito em momentos de dificuldade com questões.

Discente 5: Em relação à monitoria, há um aspecto positivo no que abrange a ajuda na resolução de exercícios, porém um aspecto negativo é a obrigatoriedade da permanência por determinado tempo. Sobre a tutoria, só observei pontos positivos. A tutora ajudou bastante na compreensão deste modo de aula, além de nós ajudar na organização do grupo.

Discente 6: Na tutoria temos uma visão geral e o professor abre nosso caminho para a melhor compreensão do conteúdo, as aulas são muito esclarecedoras e quase não saio com dúvidas de lá, caso isso aconteça, eu e minha equipe tiramos nossas dúvidas na monitoria, que também ajuda bastante com a resolução de questões. Não há nenhum aspecto negativo que eu possa comentar sobre esses recursos.

Discente 7: Na monitoria os aspectos positivos: tiram as duvidas, ajudam encontrar a resolução do problemas. Negativos: No inicio eu achei que ajudavam mas, agora as vezes há uma certa indiferença com os alunos. Não são os dois monitores. Vejo que também tem alguma dificuldade de ajudar com as questões. Sobre a tutoria, até o momento não identifiquei nenhum ponto negativo, a tutora é sempre atenciosa com todos e está sempre esclarecendo os alunos, a respeito de alguma duvida. Só elogios!!

(Respostas do discente quanto a monitoria e a tutoria, 2020). 
Percebemos, nos relatos dos discentes, dificuldade de relacionamento com um dos monitores. Constata-se, também, a aprovação da tutoria e sua contribuição para os discentes. Isso corrobora com as participações dos discentes na monitoria, com $42,86 \%$ de frequência e, na tutoria, com $81,17 \%$ de frequência.

\section{CONSIDERAÇÕES FINAIS}

Neste trabalho, buscamos responder à seguinte questão: o método da Aprendizagem Cooperativa Baseada em Problemas, tendo como suporte a teoria da Orquestração Instrumental, por meio remoto, pode apoiar o ensino e a aprendizagem de Cálculo, mais especificamente o de resolução de problemas de otimização? Para tanto, estipulamos como objetivo analisar o processo de concepção e aplicação de uma orquestração instrumental, por meio remoto, visando ao ensino de otimização, no âmbito do componente curricular de Cálculo I, por meio da metodologia aprendizagem cooperativa baseada em problemas.

A relevância da pesquisa reside no fato de integrar teoria e prática no campo da Educação Matemática. Além disso, o atual contexto da pandemia impôs uma nova realidade, não apenas nas atividades do dia a dia, mas também no ambiente acadêmico, visto que com a suspensão das atividades presenciais, houve a necessidade de uma readequação das propostas de ensino e este estudo vai ao encontro dessa necessidade.

Como limitação na aplicação deste estudo, destacamos a necessidade de os discentes terem uma internet que permita a realização das atividades propostas, como assistir às aulas síncronas, assistir às gravações das aulas, fazer downloads de vídeos e textos, participar de discussões virtuais, entre outras. Assistir às aulas usando o celular, embora seja possível, não tem a mesma qualidade de um computador ou notebook e isso, de certa forma, é um fator que pode influenciar no desempenho do discente.Após análise das soluções apresentadas, ao longo do estudo, pode-se perceber a evolução do desempenho dos discentes em cada encontro, observando o modo que resolviam por escrito cada problema e a meneira que explicavam verbalmente suas soluções aos demais colegas, o que responde positivamente à questão da pesquisa.

O trabalho realizado pela tutora teve a aprovação da maioria dos discentes enquanto o trabalho dos monitores foi satisfatório para pouco mais da metade. Em relação ao trabalho em grupo, a maioria dos discentes apresentou interesse por esse tipo de trabalho e teve uma boa relação com os demais membros do seu grupo. No tocante à metodologia da aprendizagem cooperativa baseada em problemas, os discentes se mostraram bastante satisfeitos. Por outro 
lado, em relação aos vídeos disponibilizados para os estudos prévios, antes de cada encontro, pouco mais da metade demonstrou satisfação.

Embora agregue certo grau de imprevisibilidade e aumentar o tempo de dedicação, os dados do estudo nos possibilitou perceber que a maioria dos discentes apresentou interesse pelo trabalho em grupo, mostrou-se satisfeita com a metodologia empregada e desenvolveu a habilidade de resolver os problemas propostos no estudo. Além disso, percebeu-se o aumento da satisfação discente com as atividades de ensino, melhora qualitativa na aprendizagem e seu rendimento e diminuição da evasão/desistência, demonstrando ser uma metodologia mais vantajosa em comparação com abordagens instrucionais expositivas.

\section{REFERÊNCIAS}

ABDULLAH, N. I.; TARMIZI, R. A.; ABU, R. The effects of problem based learning on mathematics performance and affective attributes in learning statistics at form four secondary level. Procedia-Social and Behavioral Sciences, v. 8, p. 370-376, 2010. https://doi.org/10.1016/j.sbspro.2010.12.052

AJAI, J. T.; IMOKO, B. I. Gender Differences in Mathematics Achievement and Retention Scores: A Case of Problem-Based Learning Method. International Journal of research in Education and Science, v. 1, n. 1, p. 45-50, 2015. Disponível em:

https://files.eric.ed.gov/fulltext/EJ1105194.pdf. Acesso em: 02 fev. 2021.

BELLEMAIN, F.; TROUCHE, L. Compreender o trabalho do professor com os recursos de seu ensino, um questionamento didático e informático. I Simpósio Latino-Americano de Didática de Matemática, 2016. Disponível em:

https://aplicacoes.ifs.edu.br/periodicos/index.php/caminhos_da_educacao_matematica/article/ view/300/204. Acesso em: 02 fev. 2021.

COHEN, Elizabeth G.; LOTAN, Rachel A. Planejando o trabalho em grupo: estratégias para salas de aula heterogêneas. Penso Editora, 2017.

CRESWELL, J. W. Projeto de pesquisa: métodos qualitativo, quantitativo e misto; Tradução Magda Lopes. - 3 ed. - Porto Alegre: ARTMED, 296 páginas, 2010.

DALL'ANNE, C.; TRENTIN, P.H. A Aprendizagem significativa no Cálculo Diferencial e Integral: Relato de experiência com a abordagem de problemas de taxa de variação na formação de engenheiros. In. GODOY, Elenilton Vieira; GERAB, Fábio. Ensino e aprendizagem de matemática no Ensino Superior: Inovações, propostas e desafios. Alta Books Editora, 2018.

DA SILVA, E. C. R. T. O processo de gênese instrumental em um ambiente online colaborativo. In: XXII Encontro Brasileiro de Estudantes de Pós-Graduação em Educação Matemática. Belo Horizonte, 2018. Disponível em: 
https://rive.google.com/file/d/1Rn4H18bd0jggCqyiCHEABK0adXj0qzlQ/view. Acesso em: 02 fev. 2021.

DE JESUS, Marcos Antonio Santos; TACACIMA, Juliana. As atitudes em relação à matemática e o desempenho em cálculo diferencial e integral de alunos de engenharia. In. GODOY, Elenilton Vieira; GERAB, Fábio. Ensino e aprendizagem de matemática no Ensino Superior: Inovações, propostas e desafios. Alta Books Editora, 2018.

DRIJVERS, Paul et al. The teacher and the tool: Instrumental orchestrations in the technology-rich mathematics classroom. Educational Studies in mathematics, v. 75, n. 2, p. 213-234, 2010. https://doi.org/10.1007/s10649-010-9254-5

ENEMARK, S.; KJAERSDAM, F. A ABP na teoria e na prática: a experiência da Aalborg na inovação do projeto no ensino universitário. In: ARAÚJO, U. F.; SASTRE, G. (Org.).

Aprendizagem Baseada em Problemas. São Paulo: Summus, 2018.

GIL, A. C. Como elaborar projetos de pesquisa. 4. ed. São Paulo: Atlas, 2008.

GLASSER, W. William Glasser. Fonte: PPD, 2017. Disponível em:

http://www.ppd.net.br/william-glasser/. Acesso em: 15 abr. 2021.

GORDON, R. Balancing real-world problems with real-world results. Phi Delta Kappan, v.79, n.5, p. 390, 1998.

JOHNSON, David W.; JOHNSON, Roger T. Instructional goal structure: Cooperative, competitive, or individualistic. Review of educational research, v. 44, n. 2, p. 213-240, 1974.

JOHNSON, David W.; JOHNSON, Roger T. Cooperation and competition: Theory and research. Interaction Book Company, 1989.

JOHNSON, David W.; JOHNSON, Roger T. Making cooperative learning work. Theory into practice, v. 38 , n. 2, p. 67-73, 1999.

JOHNSON, David W.; JOHNSON, Roger T.; SMITH, Karl A. Cooperative learning: Improving university instruction by basing practice on validated theory. Journal on Excellence in University Teaching, v. 25, n. 4, p. 1-26, 2014. Disponível em: http://personal.cege.umn.edu/ smith/docs/Johnson-Johnson-Smith-Cooperative LearningJECT-Small Group Learning-draft.pdf. Acesso em: 02 fev. 2021.

JOHNSON, David; JOHNSON, Roger; SMITH, Karl. A aprendizagem cooperativa retorna às faculdades. Change, v. 3, n. 4, p. 91-102, 1998. Disponível em:

https://www.andrews.edu/ freed/ppdfs/readings.pdf. Acesso em: 02 fev. 2021.

MERRITT, J. et al. Problem-based learning in K-8 mathematics and science education: A literature review. Interdisciplinary Journal of Problem-Based Learning, v. 11, n. 2, 2017. https://doi.org/10.7771/1541-5015.1674 
NEVES, V. J. et al. Aprendizagem Baseada em Problemas. In: NEVES, V. J., MERCANTI, L.B.(Org.). Metodologias Ativas: perspectivas teóricas e práticas no ensino superior. Campinas: Pontes Editora, 2018.

PÓLYA, G. Como resolver problemas (Tradução do original inglês de 1945). Lisboa: Gradiva, 2003.

RASMUSSEN, C.; MARRONGELLE, K.; BORBA, M. C. Research on calculus: what do we know and where do we need to go? ZDM: Mathematics Education, v. 46, n. 4, p. 507-515, 2014. https://doi.org/10.1007/s11858-014-0615-X

RIBEIRO, L. R. de C. Aprendizagem baseada em problemas (PBL): uma experiência no ensino superior. 2010.

ROBERT, A.; SPEER, N. Research on the teaching and learning of Calculus/Elementary Analsys. In: HOLTON, D. (ed.). The teaching and learning of mathematics at university level - an ICMI study, Netherlands: Kluwer Academic Publishers, 2001. p. 283-299.

TALL, David. Students' difficulties in calculus. In: proceedings of working group. 1993. p. 13-28. Disponível em:

https://www.researchgate.net/profile/David Tall/publication/242298018 Students' Difficultie $\mathrm{s}$ in Calculus Plenary presentation in Working Group 3 ICME Quebec August 1992/lin ks/546ded870cf2d5ae3670800e.pdf. Acesso em: 02 fev. 2021.

TARMIZI, Rohani Ahmad. Visualizing Student's Difficulties in Learning Calculus. ProcediaSocial and Behavioral Sciences, v. 8, p. 377-383, 2010.

https://doi.org/10.1016/j.sbspro.2010.12.053

TEIXEIRA, P. C.; MATOS, J. M. L. de; DOMINGOS, A. A orquestração instrumental dos recursos tecnológicos no ensino da matemática. Recursos na Educação Matemática, p. 291302, 2016. Disponível em:

https://run.unl.pt/bitstream/10362/21301/1/ATAS_EIEM_2016_pt_jmm_amdd.pdf. Acesso em: 02 fev. 2021.

THIOLLENT, Michel. Metodologia da Pesquisa-Ação. São Paulo: Cortez, 1985.

TROUCHE, Luc. An instrumental approach to mathematics learning in symbolic calculator environments. In: The didactical challenge of symbolic calculators. Springer, Boston, MA, 2005. p. 137-162.

\section{NOTAS}

\section{AGRADECIMENTOS}

Não se aplica.

FINANCIAMENTO

Fundação de Amparo à Pesquisa do Estado do Amazonas-FAPEAM, número do processo: 062.00930/2013, bolsista: Roberta dos Santos Rodrigues. 


\section{CONTRIBUIÇÕES DE AUTORIA}

Resumo/Abstract/Resumen: Francisco Eteval da Silva Feitosa e Roberta dos Santos Rodrigues. Introdução: Francisco Eteval da Silva Feitosa e Roberta dos Santos Rodrigues.

Referencial teórico: Francisco Eteval da Silva Feitosa e Roberta dos Santos Rodrigues.

Análise de dados: Francisco Eteval da Silva Feitosa e Roberta dos Santos Rodrigues.

Discussão dos resultados: Francisco Eteval da Silva Feitosa e Roberta dos Santos Rodrigues.

Conclusão e considerações finais: Francisco Eteval da Silva Feitosa e Roberta dos Santos Rodrigues.

Referências: Francisco Eteval da Silva Feitosa e Roberta dos Santos Rodrigues.

Revisão do manuscrito: Francisco Eteval da Silva Feitosa e Roberta dos Santos Rodrigues.

Aprovação da versão final publicada: Francisco Eteval da Silva Feitosa e Roberta dos Santos Rodrigues.

\section{CONFLITOS DE INTERESSE}

Os autores declararam não haver nenhum conflito de interesse de ordem pessoal, comercial, acadêmico, político e financeiro referente a este manuscrito.

\section{DISPONIBILIDADE DE DADOS DE PESQUISA}

O conjunto de dados que dá suporte aos resultados da pesquisa foi publicado no próprio artigo.

\section{CONSENTIMENTO DE USO DE IMAGEM}

Não se aplica.

\section{APROVAÇÃO DE COMITÊ DE ÉTICA EM PESQUISA}

Os sujeitos partícipes da pesquisa assinaram um Termo de Consentimento livre e esclarecido que foi enviado à revista.

\section{COMO CITAR - ABNT}

FEITOSA, Francisco Eteval da Silva, RODRIGUES, Roberta do Santos. Aprendizagem cooperativa baseada em problemas e orquestração instrumental no ensino de cálculo. REAMEC - Rede Amazônica de Educação em Ciências e Matemática. Cuiabá, v. 9, n. 1, e21030, janeiro-abril, 2021. https://doi.org/10.26571/reamec.v9i1.11798

\section{COMO CITAR - APA}

Feitosa, F.E.S., \& Rodrigues, R.S. (2021). Aprendizagem cooperativa baseada em problemas e orquestração instrumental no ensino de cálculo. REAMEC - Rede Amazônica de Educação em Ciências e Matemática, 9 (1), e21030. https://doi.org/10.26571/reamec.v9i1.11798

\section{LICENÇA DE USO}

Licenciado sob a Licença Creative Commons Attribution-NonCommercial 4.0 International (CC BY-NC 4.0). Esta licença permite compartilhar, copiar, redistribuir o manuscrito em qualquer meio ou formato. Além disso, permite adaptar, remixar, transformar e construir sobre o material, desde que seja atribuído o devido crédito de autoria e publicação inicial neste periódico.

\section{DIREITOS AUTORAIS}

Os direitos autorais são mantidos pelos autores, os quais concedem à Revista REAMEC - Rede Amazônica de Educação em Ciências e Matemática - os direitos exclusivos de primeira publicação. Os autores não serão remunerados pela publicação de trabalhos neste periódico. Os autores têm autorização para assumir contratos adicionais, separadamente, para distribuição não exclusiva da versão do trabalho publicada neste periódico (ex.: publicar em repositório institucional, em site pessoal, publicar uma tradução, ou como capítulo de livro), com reconhecimento de autoria e publicação inicial neste periódico. Os editores da Revista têm o direito de proceder a ajustes textuais e de adequação às normas da publicação.

\section{PUBLISHER}

Universidade Federal de Mato Grosso. Programa de Pós-graduação em Educação em Ciências e Matemática (PPGECEM) da Rede Amazônica de Educação em Ciências e Matemática (REAMEC). Publicação no Portal de Periódicos UFMT. As ideias expressadas neste artigo são de responsabilidade de seus autores, não representando, necessariamente, a opinião dos editores ou da referida universidade.

\section{EDITOR}

Dailson Evangelista Costa (D) 


\section{HISTÓRICO}

Submetido: 06 de fevereiro de 2021.

Aprovado: 31 de março de 2021.

Publicado: 17 de abril de 2021. 